University of the Pacific

Scholarly Commons

$1-1-2021$

\title{
Dental and physical therapy faculty collaborate in assessing and educating dental students on musculoskeletal disorders
}

\author{
Noëlle M. Santucci \\ University of the Pacific, nsantucci@pacific.edu \\ Justin Jellin \\ University of the Pacific, j_jellin@u.pacific.edu \\ Todd E. Davenport \\ University of the Pacific, tdavenport@pacific.edu
}

Follow this and additional works at: https://scholarlycommons.pacific.edu/shs-all

Part of the Medicine and Health Sciences Commons

\section{Recommended Citation}

Santucci, Noëlle M.; Jellin, Justin; and Davenport, Todd E., "Dental and physical therapy faculty collaborate in assessing and educating dental students on musculoskeletal disorders" (2021). All Faculty Scholarship. 6.

https://scholarlycommons.pacific.edu/shs-all/6

This Article is brought to you for free and open access by the School of Health Sciences at Scholarly Commons. It has been accepted for inclusion in All Faculty Scholarship by an authorized administrator of Scholarly Commons. For more information, please contact mgibney@pacific.edu. 


\section{Dental and physical therapy faculty collaborate in assessing and educating dental students on musculoskeletal disorders}

\section{Noëlle M. Santucci DDS, MA, RDH ${ }^{1}$ MPH $^{3}$}

Justin Jellin DPT ${ }^{2}$

\author{
Todd E. Davenport PT, DPT,
}

${ }^{1}$ Department of Preventive and Restorative Dentistry, Arthur A, Dugoni School of Dentistry, University of the Pacific, San Francisco, California, USA

${ }^{2}$ Department of Diagnostic Sciences, Arthur A, Dugoni School of Dentistry, University of the Pacific, San Francisco, California, USA

${ }^{3}$ Department of Physical Therapy, Thomas J. Long School of Pharmacy \& Health Sciences, University of the Pacific, Stockton, California, USA

\section{Correspondence}

Dr. Noelle Santucci, DDS, MA, RDH, Associate Professor in the Department of Preventive and Restorative Dentistry, University of the Pacific, Dugoni School of Dentistry, 155 Fifth Street, 4G5 San Francisco, CA 94103, USA. Email:nsantucci@pacific.edu

\begin{abstract}
Introduction: Research shows $54 \%$ to $93 \%$ of practicing dentists suffer from musculoskeletal disorders (MSDs), with many developing afflictions early in their careers. Studies also show that dental students are developing MSDs early in their professional education.

Objective: The research goal was to quantify the prevalence, anatomical location and initial onset of MSDs among first-year dental students. The study also assessed the students' self-reported opinion as to whether there were enough educational touchpoints to improve their ergonomics in daily activities.

Methods: At the conclusion of a 9-month preclinical restorative course, that included 2 lectures on MSDs, ergonomics, and postural cueing sessions, a dental and physical therapy faculty member administered a survey to 143 first-year dental students. This survey included questions about the history and presentation of the students' MSD symptoms and their opinion on the relative value of the educational interventions.
\end{abstract}

Results: There was a $96.5 \%$ response rate to the survey with $87.8 \%$ of students reporting mild to moderate pain. The cervical spine (41.7\%) and hands (42.4\%) were the most common areas afflicted. $55.4 \%$ reported pain commencing 1 month after starting in the simulation clinic. Over $60.9 \%$ of students "agreed" or "somewhat agreed" that the 2 sessions of hands-on ergonomic educational interventions resulted in improved biomechanics and students requested additional educational resources.

Conclusion: Dental students are developing MSDs as soon as 1 month after commencing dental school. Dental education should include ongoing ergonomic training throughout the curriculum to help students prevent MSDs.

\section{KEYWORDS}

educational assessment, ergonomics, interprofessional relations, musculoskeletal disorders, postural cueing, preclinical dental education, teaching method

\section{1 | INTRODUCTION}

Over $54 \%$ of dentists will develop some type of musculoskeletal disorder (MSD) during their careers. ${ }^{1-5}$
Depending on the study, numbers vary and can go as high as $93 \%{ }^{2,6}$ This can lead to dentists terminating clinical practice earlier than they desired. ${ }^{7}$ In a systematic review, Hayes et al. showed that the most prevalent regions for 
pain among practicing dentists was the back (36.3\%-60.1\%) and neck (19.8\%-85\%), while the hands and wrists were the most prevalent regions for practicing dental hygienists $(60 \%-69.5 \%){ }^{8}$

Valachi and Valachi's 2003 article established a postural blueprint for dental professionals to prevent the development of MSDs. ${ }^{9-11}$ These postures are generally taught and accepted as the standard for proper ergonomics. Despite these generally accepted standards, MSDs continue to plague dentists and dental students. Over the last 5 years, the University of the Pacific's Dugoni School of Dentistry has seen an increase in the number of preclinical dental students voicing concerns about pain and discomfort in the neck, hands, and back. An initial informal 2-question survey conducted by administration in 2016 asked 142 firstyear dental students if, since beginning dental school, they had experienced new pain in the area of the hands, fingers, wrists, arms, shoulders, neck, and/or upper or lower back. Of the 111 respondents, 93 reported pain in 1 or more areas of the body. The hands, fingers, and thumbs were the most common areas affected, followed by the neck, back, and wrists. The second question asked what provided relief to their symptoms. Eighty-four said stretching and 62 said rest improved their affliction. Voluntary written comments mentioned the weight of the handpiece, doctor chair design, or preparing teeth in a typodont caused their pain.

Several of those students sought and received care from their physicians and physical therapists for these issues. Some were instructed by their doctors to limit their preclinical activities or to completely rest from preparing teeth on a typodont for up to 8 weeks. This respite from preparing teeth required the students to later remediate the preclinical course to catch up with the class.

Since the 2016 survey, the Preclinical Restorative Course Directors received and observed from subsequent cohorts more frequent self-reporting complaints of pain or discomfort during simulated practice on typodonts. Becoming aware of these issues, 2 faculty members, the Preclinical Restorative Course Director (DDS) and the Doctor of Physical Therapy (DPT), collaborated to investigate the apparent rise in musculoskeletal disorders among first-year dental students.

\section{2 | METHODS}

Two faculty members from the University of the Pacific, Dugoni School of Dentistry, the Course Director of the first-year preclinical integrated restorative simulation course (DDS) from the Department of Preventive and Restorative Dentistry, and the Doctor of Physical Therapy (DPT) from the Department of Diagnostic Sciences, collaborated to survey 143 first-year dental students on the symptoms, anatomical location, onset, and cause of their MSDs. The students were also queried as to whether 2 sessions of hands-on training with postural cueing helped provide them with tools to better position themselves in the simulation clinic and help address their developing MSDs.

The DDS and DPT co-presented a 1-hour lecture on dental ergonomics and MSDs in the first month of the firstyear preclinical integrated restorative simulation course. Though prior classes had been presented with lectures on ergonomics, for this cohort, the DPT added information about the types of MSDs that were common to dentistry, and related symptoms with specific incorrect ergonomic principles.

What was new to the curriculum was the addition of real-time postural corrective cueing simultaneously by both the DDS and the DPT. Postural cueing is used by physical therapists to evaluate patients in real time and draw comparisons between their incorrect ergonomics and the resulting or potentially developing MSDs. The 2 faculty members rotated through the simulation clinic twice during the dental students' 9-month course, working with groups of 18 students at a time. These sessions began with a 20-minute verbal interactive review on the subjects of ergonomics and MSDs. It also included time for students to ask questions. The DPT and DDS remained with the group of 18 students for up to 30 minutes giving realtime corrections on posture, chair positioning, loupe fit, and ergonomics. They also helped those students who expressed concerns of pain, make the associations with their ergonomically incorrect postures.

At the end of the 9-month restorative course, a descriptive study via a survey was administered. Exempt status \#18-84 for the research method was obtained from the University's Internal Review Board. Of the 143 members of the first-year dental class, 138 students signed a consent form and voluntarily filled out the questionnaire. This was accomplished during scheduled class time during which a researcher was consistently present to review instructions and answer any questions. The survey took 5-20 minutes to complete.

There were 5 sections to the questionnaire. Section 1 (see Table 1) of the survey asked general questions about the history and presentation of their symptoms including the location, the precipitating factors, the intensity of the pain, when and what caused symptoms and if current educational modalities were helpful. If in Section 1, the student answered "yes" to having pain, they were then asked to answer the questions in Sections 2-5 that pertained to them. Sections $2-5$ of the questionnaire consisted of adapted orthopedic survey questions (functional outcome measures). These functional outcome measurement questions were selected due to the vast data supporting the validity of patient responses. The sections 
TABLE 1 Section 1 of Survey

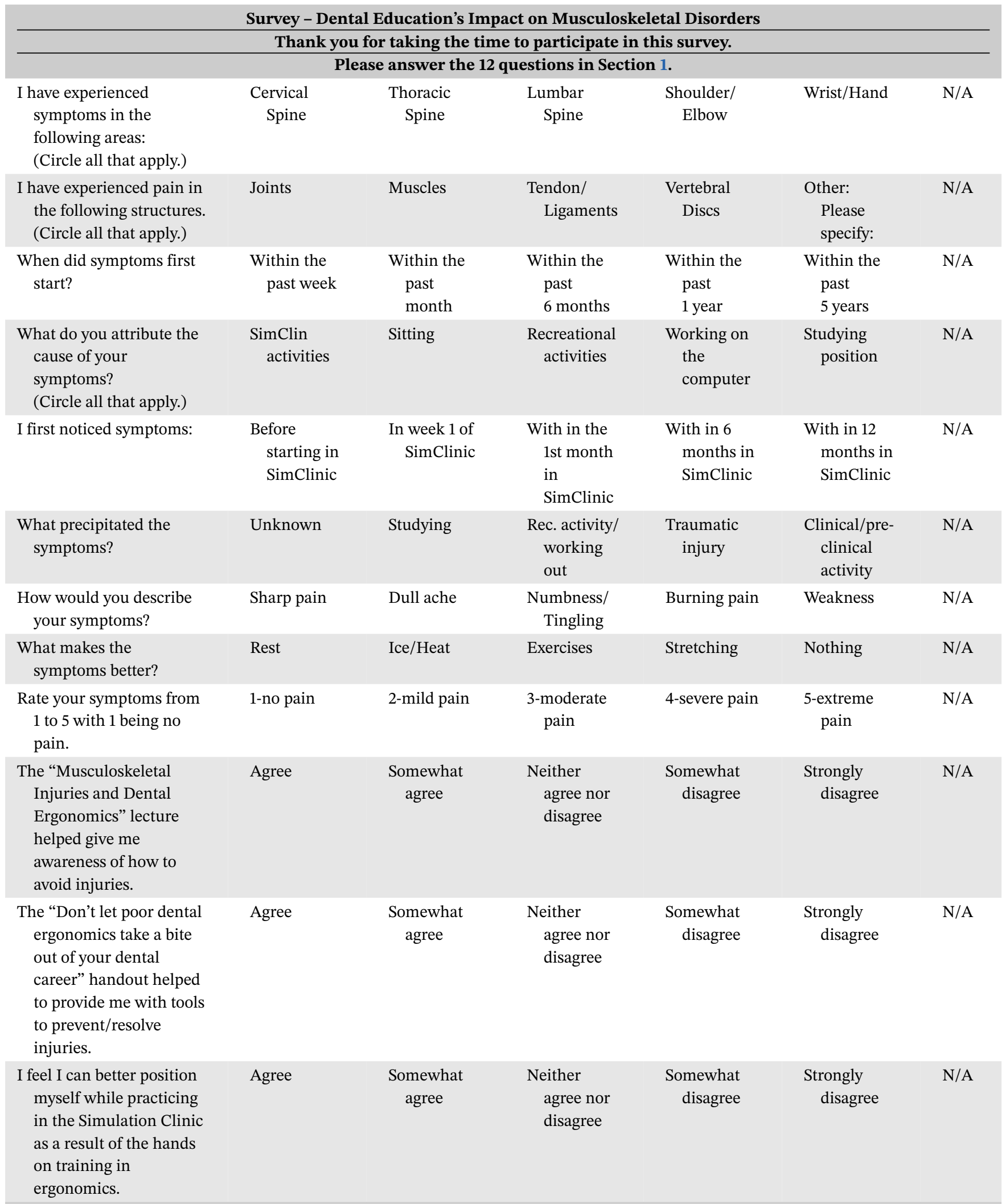




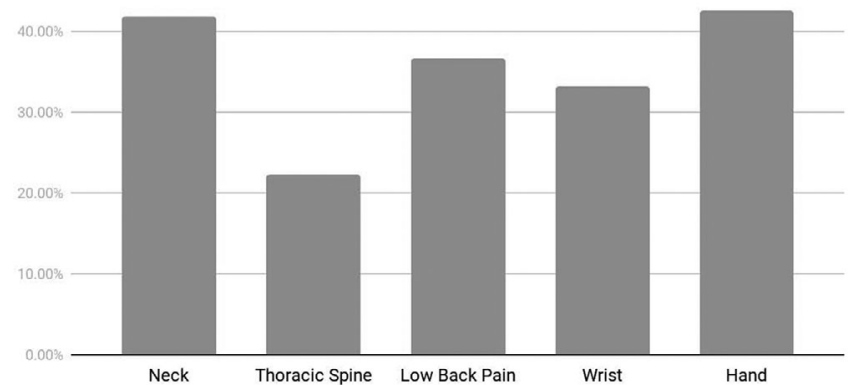

F I G U R E 1 Student reporting mild disability and mild to moderate pain by body region

were broken down as follows: Section 2-Neck Index (NDI), Section 3-Lower Extremity Functional Scale (LEFS), Section 4-Disabilities of the Arm Shoulder Hand (DASH), Section 5-Oswestry Index (ODI) for the Back and Neck. Those questions served to identify and verify the location, duration, intensity of the pain, aggravating factors, type of pain experienced, and the types of functional limitations the students were experiencing. The indexes were slightly adapted by the DDS and DPT to better meet the needs of the dental population being queried. This allowed for the development of pointed questions to ask dental students relevant to their activities of daily function in and outside of school. In the adaption of these questions, the DPT gave advice on how to gather data on functional outcome measurements and the DDS gave input on what positions, actions, and movements the students used to practice dentistry.

\section{3 | RESULTS}

Descriptive statistics were used to analyze the data. Included in the analysis were means, standard deviations, and $95 \%$ confidence intervals for continuous data and numerical counts accompanied by percentages for categorical data.

Of the 143 students enrolled in the class, 138 students responded voluntarily to the survey. Of those, 69 were females, 73 were males. $87.8 \%$ of the students reported mild to moderate pain in at least 1 body part. These students had on average 1.94 affected body parts. Students reported mild-moderate pain in the wrist/hand $(42.4 \%)$ cervical spine/neck (41.7\%), lumbar spine (36.7\%) and thoracic spine (22.3\%) (see Figure 1).

The survey revealed that $55.4 \%$ of the students' pain started after 1 month of commencing their preclinical simulation education. Of the $87.8 \%$ that reported pain, $54.0 \%$
Cause of Pain in Student Population

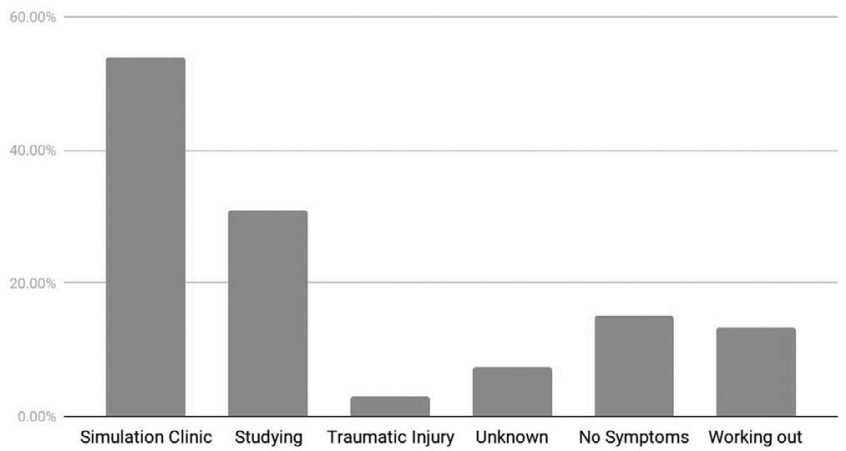

F I G U RE 2 Cause of pain in student population

Employed Pain Reduction Techniques

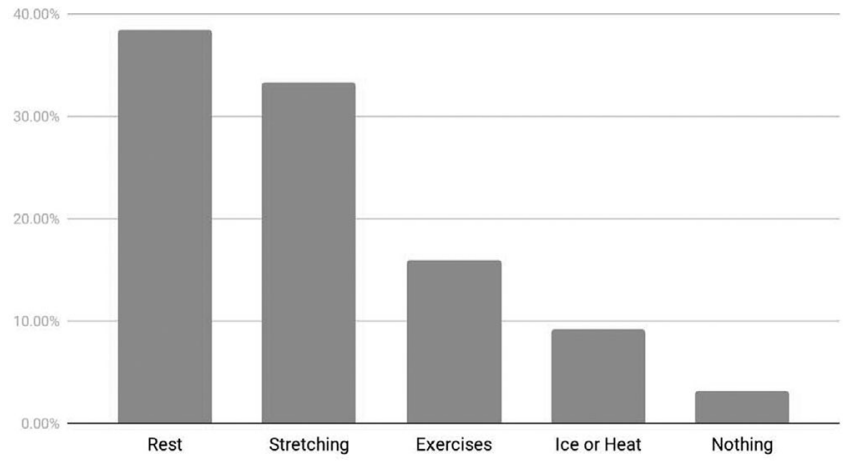

Was Hands-On Training Helpful for Positioning in the SimClinic

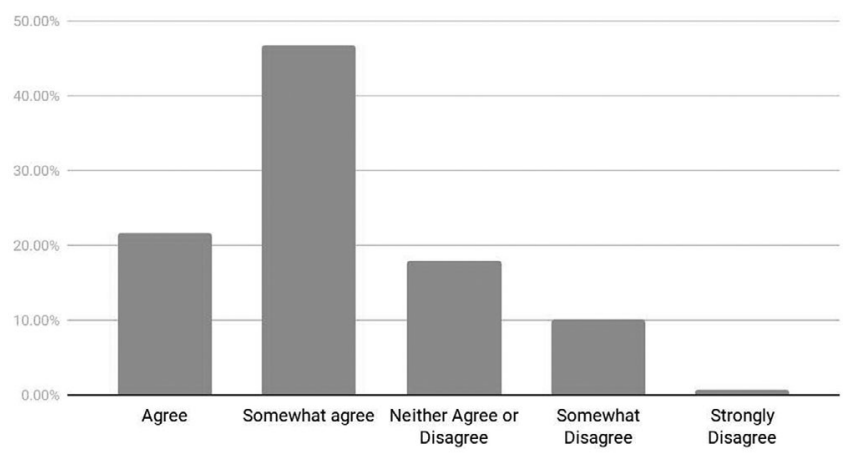

F I G U RE 3 A. Employed pain reduction techniques; B. Was hands-on training helpful for positioning in the simclinic?

stated it was caused by preparing teeth on a typodont in the Simulation Clinic (see Figure 2). Additionally, students reported that studying (30.9\%), physical exercise (13.3\%), insidious onset (7.3\%), and traumatic injury (3.0\%) precipitated their symptoms. When the students were asked what relieved their pain in the 9-months prior to the study, 38.5\% stated rest to be the best solution for correcting their symptoms (see Figure 3A). This was followed by stretching, exercise, ice, and heat.

Additionally, $68.8 \%$ of the students reported that they "agreed" or "somewhat agreed" that the lecture material 
on "Musculoskeletal Injuries and Dental Ergonomics" helped to build awareness of how to avoid MSDs. 60.9\% of the students "agreed" or "somewhat agreed" that the 2 sessions of hands-on training with postural cueing helped provide them with tools to better position themselves in the simulation clinic (see Figure 3B). Voluntary comments included the request for additional postural corrective cueing sessions.

\section{4 | DISCUSSION}

Similar to other studies on dental students, ${ }^{12-18}$ our research study revealed that nearly $90 \%$ of the students had some type of MSD, with the spine and wrist being the most affected area. In accordance with orthopedic research, incorrect postures (or poor body mechanics) are risk factors for developing MSDs. ${ }^{16}$ During the postural cueing sessions, the DPT commonly observed students with musculoskeletal compensations of forward head posture and rounded shoulders. These incorrect body mechanics place excessive pressure on anatomical structures not designed to maintain correct posture. The result is compensatory anatomical positions and excessive musculoskeletal stress, specifically to the vertebral discs. Common errors the DDS observed affecting the students' body mechanics included incorrect chair height and seat tilt angle along with incorrect positioning of the backrest. This often caused the students to sit in positions that increased thoracic spine kyphosis causing a rounded upper back and diminished lumbar spine lordosis causing a slouched low back. Additionally, students were observed gripping handpieces overly tight with excessive wrist flexion. This incorrect ergonomic position can cause increased pressure within the carpal tunnel and damage anatomical structures such as the median nerve. ${ }^{16}$

While students found educational content and methods beneficial, through self-reporting, they requested more information in the curriculum on MSDs, dental ergonomics, and corrective interventions. Students sought additional postural cueing sessions and felt that 2 touchpoints during a 9-month course was insufficient.

An unexpected data point from this research that drew attention was that $38.5 \%$ of the students reported "rest" to be the best solution for resolving their musculoskeletal symptoms. There are 2 types of rest useful in addressing MSDs. The first is used to avoid overuse injuries and includes short periods of inactivity. Short periods of rest are one of the many treatment options to prevent repetitive stress injuries and are advised during daily practice to mitigate deleterious MSDs, specifically of the soft tissue. ${ }^{19}$ They should be taken during or after a lengthy dental procedure and in between scheduled patients. This is similar to a weightlifter taking a break between lifting sets of weights. ${ }^{20}$ The second type comprises extended periods of rest after sustaining a major traumatic injury. Extended periods of inactivity are only indicated in extreme cases of traumatic injury. ${ }^{18}$ Long periods of rest should not be utilized to resolve soft tissue musculoskeletal injuries. ${ }^{17}$ Important factors in determining the extent of the recommended rest periods include the anatomical location, type of injury, and onset of epidemiological symptoms. While extended periods of rest can improve musculoskeletal inflammation and the immediate symptoms experienced by the student, addressing the root cause of the aggravating factors is best in resolving MSDs. In dentistry this would mean evaluating the ergonomics of the student, correcting deficiencies in real time and modifying any equipment as deemed necessary. If not, chronic pain cycles of fear and avoidance ${ }^{21}$ can develop where multiple courses of inflammation, pain, muscle atrophy, and re-injury can occur. ${ }^{22}$ This cycle results in weakened anatomical structures that are prone to re-injury. Remedying mobility and stability impairments in the musculoskeletal system through therapeutic strengthening and stretching are the most effective interventions in conjunction with making ergonomic adjustments to the workplace set up. ${ }^{23}$ In an educational setting, the knowledge gap we observed in this study among students could be closed by adding evidence based research on the cause, prevention and treatment options for MSDs, into the curriculum.

If a student complains of a musculoskeletal disorder and/or is currently seeking medical attention for an MSD, it is important to take a more in-depth look at that student's grasp of ergonomic principles and injury management. This would entail faculty observing the student while s/he was practicing on mannequins in the simulation clinic or treating patients in the clinic. These focused observations should go on over the course of several weeks. Faculty would give the student real-time corrections to institute better ergonomic habits. Additionally, if equipment modifications were needed, then those adaptations could also be applied. Treatment alone without changing the incorrect ergonomics causing the injury could lead to a recurrence of that injury once medical treatment is complete. Thus the faculty and the treating medical provider should work together to help the student resolve symptoms and mitigate future injury. This information could potentially limit the number of students out on "rest" for weeks at a time. It could also obviate the need for student remediation of the missed curriculum due to physical injury.

While this study had some significant findings, it also had some limitations. The historically validated LEFS, DASH, Neck, and Back Indexes were modified to be more dentally applicable. While these newly formulated questions were helpful to learn more about student symptoms, 
it caused the questionnaire to lose some of its validity. Therefore, only Section I of the survey was used in our research. These indices could provide an area of future research and interprofessional collaboration by working to validate a dentally focused LEFS, DASH, and Neck and Back Indices.

Another limitation of this study was that the survey was given to the students after the completion of their 9-month restorative course. All students did not take the survey at the same time, which could have presented different levels of MSD severity and knowledge recall. A different approach would be to survey the students at the commencement of their education, repeating it several times throughout the pre-clinical course and at the course conclusion. This could have potentially given more information as to the onset, characteristics, and details of their symptoms.

While this study showed that students had an increased awareness of how to avoid musculoskeletal injuries, it also could have focused on whether the IPE collaboration was effective in mitigating symptoms or enhancing students' ergonomics. A more specific study could have compared ergonomic evaluations performed by a DDS faculty alone to those performed collaboratively by a DDS and DPT faculty. The study could assess specifically whether the presence and expertise of the DPT alone made the dental students experience fewer MSDs and have better management strategies for their various musculoskeletal pain or discomfort.

As dental educators, it is our duty to graduate students that will not only be successful in the dental profession but will be able to practice throughout their career pain-free. The investigatory efforts that we have started in this research could continue by monitoring the development of MSDs throughout the 4 years of the students' dental education. This could potentially answer questions such as: Are additional cases of MSDs developing after students enter the clinic? Are proper ergonomics assessed during clinical practice or is it not a part of clinical faculty's focus? Does the expertise of the DPT need to be extended into students' clinical experiences? A future study could examine preclinical and clinical dental faculty's knowledge level of ergonomics and corrective interventions in addressing students' musculoskeletal disorders. If a knowledge gap exists, more robust faculty training and educational endeavors could be implemented. This effort to educate faculty could potentially help address and reduce the number of students sustaining injuries and could aid our graduates to practice without disabilities or functional limitations throughout their careers.

\section{5 | CONCLUSION}

Dental students are developing MSDs early in their dental education. There is also a knowledge gap among students that rest alone is the solution to their MSDs. As dental educators, it is our duty to help students understand the importance of developing correct ergonomic habits to allow them to practice without being limited by disability or pain. ${ }^{14-16,24-27}$ Ergonomic educational interventions should be provided to students early in their curriculum. Reinforcing these principles consistently throughout the students' 4-year educational career could help mitigate MSDs, maintain graduates' longevity in practice and avoid their premature retirement. $5,13-14,16,28$

\section{DIS C L OS URES}

Authors have no disclosures.

\section{RE F E RE N C ES}

1. Movahhed T, Dehghanib M, Arghami S, Arghami A. Do dental students have a neutral working posture? J Back Musculoskelet Rehabil. 2016;29(4):859-864.

2. De Sio S, Traversini V, Rinaldo F, et al. Ergonomic risk and preventive measures of musculoskeletal disorders in the dentistry environment: an umbrella review. PeerJ. 2018;15(6):e4154.

3. Bozkurt S, Demirsoy N, Günendi Z. Risk factors associated with work-related musculoskeletal disorders in dentistry. Clin Invest Med. 2016;39(6):S192-S197.

4. Gopinadh A, Devi KN, Chiramana S, Manne P, Sampath A, Babu MS. Ergonomics and musculoskeletal disorder: as an occupational hazard in dentistry. J Contemp Dent Pract. 2013;14(2):299303.

5. Valachi B, Valachi K. Mechanisms leading to musculoskeletal disorders in dentistry. J Am Dent Assoc. 2003;134(10):1344-1350.

6. Partido BB, Wright BM. Self-assessment of ergonomics amongst dental students utilising photography: RCT. Eur J Dent Educ. 2018;22(4):223-233.

7. Carpentier M, Aubeux D, Armengol V, Perez F, Prud'homme T, Gaudin A. The effect of magnification loupes on spontaneous posture change of dental students during preclinical restorative training. J Dent Educ. 2019;83(4):407-415.

8. Hayes MJ, Cockrell D, Smith DR. A systematic review of musculoskeletal disorders among dental professionals. Int J Dent Hygiene. 2009;7:159-165.

9. Valachi B, Valachi K. Preventing musculoskeletal disorders in clinical dentistry: Strategies to address the mechanisms leading to musculoskeletal disorders. J Am Dent Assoc. 2003;134(12):1604-1612.

10. Cervera-Espert J, Pascual-Moscardó A, Camps-Alemany I. Wrong postural Hygiene and ergonomics in dental students of the university of Valencia (Spain) (part I). Eur J Dent Educ. 2018;22(1):e48-e56.

11. Offner D, Strub M, Rebert C, Musset AM. Evaluation of an ethical method aimed at improving hygiene rules compliance in dental practice. Am J Infect Control. 2016;44(6):666-670. 
12. Rising DW, Bennett BC, Hursh K, Plesh O. Reports of body pain in a dental student population. J Am Dent Assoc 2005;136(1):8186.

13. de Carvalho MV, Soriano EP, de França Caldas A, Jr, Campello RI, de Miranda HF, Cavalcanti FI. Work-related musculoskeletal disorders among brazilian dental students. J Dent Educ. 2009;73(5):624-630.

14. Diaz-Caballero JA, Gómez-Palencia IP, Díaz-Cárdenas S. Ergonomic factors that cause the presence of pain muscle in students of dentistry. Med Oral Patol Oral Cir Bucal. 2010;15(6):e906-911.

15. Botta AC, Presoto CD, Wajngarten D, Campos JADB, Garcia PPNS. Perception of dental students on risk factors of musculoskeletal disorders. Eur J Dent Educ. 2018;22(4):209-214.

16. Ng A, Hayes MJ, Polster A. Musculoskeletal disorders and working posture among dental and oral health students. Healthcare. 2016;4(1):13.

17. Buckwalter JA. Activity vs. rest in the treatment of bone, soft tissue and joint injuries. Iowa Orthop J. 1995;15:29-42.

18. Silbernagel KG, Crossley KM. Proposed return-to-sport program for patients with midportion achilles tendinopathy: rationale and implementation. J Orthop Sports Phys Ther. 2015;45(11):87686.

19. Pejčić N, Petrović V, Marković D, et al. Assessment of risk factors and preventive measures and their relations to work-related musculoskeletal pain among dentists. Work. 2017;57(4):573-593.

20. Willardson JM. A Brief Review: How Much Rest between Sets? Strength Cond J. 2008;30(3);44-50.

21. Vlaeyen JWS, Crombez G, Linton SJ. The fear-avoidance model of pain. PAIN. 2016;157(8):1588-1589.
22. Whitten CE, Donovan M, Cristobal K. Treating chronic pain: new knowledge, more choices. Perm J. 2005;9(4):9-18.

23. Martin RL, Chimenti R, Cuddeford T, et al. Achilles pain, stiffness, and muscle power deficits: midportion achilles tendinopathy. Revision 2018. J Orthop Sports Phys Ther. 2018;48(5):A1-A38.

24. Presoto CD, Wajngarten D, Domingos PAS, Campos JADB, Garcia PPNS. Dental students' perceptions of risk factors for musculoskeletal disorders: adapting the job factors questionnaire for dentistry. J Dent Educ. 2018;82(1):47-53.

25. Garcia PPNS, Wajngarten D, Campos JADB. Development of a method to assess compliance with ergonomic posture in dental students. J Educ Health Promot. 2018;7(44).

26. Melis M, Abou-Atme YS, Cottogno L, Pittau R. Upper body musculoskeletal symptoms in Sardinian dental students. J Can Dent Assoc. 2004;70(5):306-310.

27. Carney KK. Dentistry as an endurance sport. J Calif Dent Assoc. 2016;44(7):397-398.

28. Dylla J, Forrest JL. Fit to sit-strategies to maximize function and minimize occupational pain. J Mich Dent Assoc. 2008;90(5):3845.

How to cite this article: Santucci NM, Jellin J, Davenport TE. Dental and physical therapy faculty collaborate in assessing and educating dental students on musculoskeletal disorders. J Dent Educ. 2021;85:53-59. https://doi.org/10.1002/jdd.12387 